\title{
A MAQUINAÇÃO A PARTIR DO ABANDONO E DO ESQUECIMENTO DO SER EM HEIDEGGER
}

\author{
Rodrigo Amorim Castelo Branco ${ }^{1}$ \\ Universidade de Brasília (UnB) \\ (D) https://orcid.org/0000-0003-0309-0059 \\ E-mail: rodrigocasbr@hotmail.com
}

\section{RESUMO:}

O presente artigo tem como propósito discutir sobre as origens e os desdobramentos da maquinação (Machenschaft) na história do pensamento ocidental. Para tanto, fazemos uma leitura ontológicafenomenológica da questão da técnica a partir das meditações de Heidegger, sobretudo na obra Contribuições à Filosofia (Do Acontecimento Apropriador), publicada em 1989. As reflexões aqui presentes pensam a maquinação como uma disposição que, em sua gênese, revela-se como um acontecimento além da força e da vontade do homem, destacando o abandono e o esquecimento do ser como eventos fundantes da história. Buscamos evidenciar o verdadeiro sentido da condição histórica dos entes no contexto contemporâneo ao demonstrarmos como o ocultamento e a ausência do ser representam o fundo originário da existência. Assim, o ponto fundamental deste texto é a indicação de que o vigor da ausência essencial pode possuir robustez mais profunda do que a presença de qualquer ente.

PALAVRAS-CHAVE: Heidegger; Maquinação; Técnica; Gigantesco; Ciência.

\section{MACHINATION FROM THE ABANDONMENT AND FORGETFULNESS OF BEING IN HEIDEGGER}

\begin{abstract}
:
The purpose of this paper is to discuss the origins and consequences of machination (Machenschaft) in the history of Western thought. For this purpose, we make an ontological-phenomenological reading of the question of technique from Heidegger's meditations, especially in his Contributions to Philosophy (Of the Event), published in 1989. The reflections here think of machination as a disposition that, in its genesis, reveals itself as an event beyond the strength and will of man, highlighting the abandonment and forgetfulness of being as founding events of history. We seek to show the true meaning of the historical condition of the entities in the contemporary context by showing how the occultation and the absence of being represent the original background of existence. Thus, the fundamental point of this text is the indication that the force of essential absence may have more robustness than the presence of any entity.
\end{abstract}

KEYWORDS: Heidegger; Machination; Technique; Gigantic; Science.

\footnotetext{
${ }^{1}$ Doutorando em Filosofia e professor substituto na Universidade de Brasília (UnB), Brasília - DF, Brasil.
}

BRANCO, Rodrigo Amorim Castelo. A maquinação a partir do abandono e do esquecimento do ser em Heidegger. Griot : Revista de Filosofia, Amargosa - BA, v.19, n.2, p.22-40, junho, 2019. 


\section{Introdução}

O texto em questão busca demonstrar o pensamento heideggeriano sobre a origem da maquinação (Machenschaft), isto é, da técnica e de suas funcionalidades calculantes que buscam fazer, produzir, computar e explorar o real. Levando em conta sobretudo as meditações de Heidegger na obra Contribuições à Filosofia (Do Acontecimento Apropriador), publicada em 1989, evidenciamos como a maquinação se dá a partir do deixar-ser da própria essência do seer/Seyn ${ }^{2}$. O deixa-ser aqui indica a retração do seer, que ao se dar, permite que a maquinação aconteça e, assim, ingressamos em uma contemporaneidade líquida, produtiva, mecanizada e atômica. Esse é o ápice da maquinação no gigantesco ${ }^{3}$, aquilo que não conhece limites, pois a factibilidade impera nos nossos tempos. A ciência com seus métodos, sistemas e funcionalidades, que buscam determinar, prever e manipular a natureza se torna um símbolo do gigantesco. Assim, o ente passa a ser o disponível para o poder de mensurar, catalogar, criar estatísticas e formar padrões.

A nossa reflexão se dirige ao escopo da maquinação (técnica), que surge para o asseguramento total em direção à aniquilação de incertezas e em busca da correção. Nesse sentido, vemos que os membros da sociedade humana adentram na era da ausência de questão, que é fruto do encantamento com a maquinação (Machenschaft). A certeza de si mesmo (Selbstgewissheit) se torna fulcral, tudo é regido pelo finalismo do cálculo e a verdade essenciante (Seyn) não se apresenta mais como questão digna do pensar. Heidegger ressalta que esse maravilhamento maquinal é um modo de essenciação do ser. "Mesmo o tom ressonante do desprezível precisa ser afastado, ainda que a maquinação favoreça a inessência do ser" (HEIDEGGER, 2015, p. 125). Essa inessência, comportada na atividade maquinal, não deve ser desvirtuada e pensada de forma pejorativa e depreciativa, na medida em que a própria inessência é fundamental para a essência do ser se dar. Eis a questão fundamental e ambígua nas meditações de Heidegger que abordamos neste texto.

Enfim, o propósito central do presente trabalho é discutir acerca da ambiguidade essencial no pensamento de Heidegger, que se encontra na questão do abandono e do esquecimento do ser como origem essencial e inessencial da maquinação. Fazemos uma abordagem ontológica da Machenschaft, elucidando como

2 "O ser na viravolta - Seyn (Heidegger, por vezes, escreve-o com y para distingui-lo do ser de antes da viravolta) também chamado acontecimento-apropriação, decisão, é o ser do qual emerge, como de uma identidade, o ser e o homem de antes da viravolta. Esse ser, que é identidade originária, é a origem, a fonte, a diferença de que emergem os polos: ser-ente. Esse ser e sua verdade em sua relação com o homem são a esfera radical em que se dá o destino e todo o destinal na história da relação ser-homem. É esse ser (Seyn) que acontece como velamento do velamento do ser (Sein) no desvelamento dos entes, no desvelamento no ser-aí. O acontecer desse ser (Seyn) é o acontecimento da viravolta. O pertencer do ser à clareira do ocultar-se no tempo (ocultar-se que se desvela no tempo), o produzir o tempo, como ocultar-se desvelante, a presença (ser) são instaurados pelo ser (Seyn) como origem, como acontecimento-apropriação. Este ser é o velamento do velamento que se desvela nos entes. É a partir dele que surge o esquecimento do ser, ser aqui entendido como antes da viravolta, porque o ser (Seyn) vela o próprio velar-se do ser (Sein) no desvelamento dos entes. É deste ser (Seyn) que emerge o destino, é dele que emerge a história do esquecimento do ser, é ele que dá ser e dá tempo. É ele que instaura a história do ser, que sempre é história do esquecimento do ser. E isso não por distração de algum homem [...], mas por decisão do ser (Seyn) que acontece-apropria" (STEIN, 2011, p. 84). Na tradução da obra Beiträge zur Philosophie (Vom Ereignis) para Contribuições à Filosofia (Do acontecimento apropriador) por Marco Antônio Casanova, Seyn é apresentado com a grafia seer.

${ }^{3}$ Engrandecimento a partir da expansão da factibilidade do ente. 
ela é um exercício de liberdade do homem a partir do abandono do ser, isto é, de sua ausência fundante. Desse evento de retração originária, dá-se o esquecimento do ser por parte do ente humano, esquecimento este que já parte da queda da alétheia com o advento do jugo do eidos platônico sobre o desvelamento da natureza.

\section{O abandono do seer: o primado do ente na maquinação}

A maquinação é abordada por Heidegger na estrutura (Fügung) da ressonância (der Anklang) nas Contribuições à Filosofia. Nessa estrutura, o ser-aí (Dasein) reconhece a sua indigência como pobreza (finitude), já que ela traz à aparição o velado do esquecimento do seer (Seynsvergessenheit), a partir do qual a essência originária ressoa no ente como aquilo que mais esteve retraído. Assim, pergunta Heidegger (2015, p. 106): “A ressonância para quem? Para onde? A ressonância do seer no abandono do ser". Mas como o abandono do ser acontece? Ele emerge da inessência (Unwesen) do seer a partir da maquinação (Machenschaft). Essa inessência se origina da ausência originária, mas, ao mesmo tempo, não acontece apenas por esse retraimento. Tal ambiguidade se dá, pois esse acontecimento indica a própria verdade do seer e o modo de sua vigência. $O$ inessencial parte das representações maquinais como produtos do homem reificado no cálculo (Berechnung).

Dissemos que o ponto central em debate neste artigo é a maquinação. Todavia, o que indica esse termo tão usado por Heidegger nas Contribuições à Filosofia? Em resposta a essa questão, já podemos ver um modo inicial de maquinação no Ocidente entre os gregos a partir da téchne. Trata-se da presentificação constante do saber-fazer (téchne) na dimensão do produzir (poiésis), que constrói em constância como factibilidade. A téchne como técnica contrasta com a physis, isto é, com os entes vigorando a partir de si mesmos. A primeira indica não um fazer puramente, mas um saber (wissen) que nos orienta na relação com a physis, desvelando-a a cada momento. O técnico, o possuidor de téchne, é aquele que tem o conhecimento de como revelar os entes e de como produzi-los. Esta compreensão de téchne perdura e, modernamente, instaura-se como Technik. "A tecnologia não é, primordialmente, um modo de fazer coisas, mas um modo de revelar as coisas que precede o fazer" (INWOOD, 2002, p. 181). O "revelar" é o que caracteriza a técnica e o saber-fazer (wissen-machen) da maquinação, uma vez que ela toma para si a posição de desveladora do real e de produtora do ente.

Maquinação, inicialmente, não está relacionada à máquina (Maschine). Pelo contrário, ela nos conduz ao mundo demasiado humano das vivências (Erlebnisse). Essas vivências passam a forjar fundamentos com os conceitos ens creatum, res cogitans (animal rationale), res extensa, Res infinita. Máquinas e tecnologias são derivações das Erlebnisse e aqui o ente se encanta com as funcionalidades e dispositivos das representações. Nesse aspecto, o encantamento não advém do essencial (Seyn), mas das modulações da vivência. Isso representa o acontecimento do abandono do ser no esquecimento do seer. Desse modo, ingressamos na estação de inquestionabilidade pelo ingresso no âmbito das metas vivenciais: "A atividade incansável, contínua, acelerada e propagandeada que se revela em todos os campos, 
enriquecida [...] de maneira cada vez mais ampla e notável, é indício da forma como nosso modo de ser se submete a uma maquinação" (RÜDIGER, 2002, p. 35).

A maquinação é a recusa à dádiva da retração do seer. Ela almeja aquilo que está presente à vista como visado e calculado por meio da produção e da execução da vontade. Essa situação é pensada a partir do próprio fundamento que não é fenomenológico, que não é a coisa mesma do pensar (Sache des Denkes), pois é o próprio ente enquanto tal representado. A maquinação a tudo busca manipular (representar), que até mesmo o que a ela resiste se torna material para a sua ampliação e domínio, visando o "progresso" cultural e tecnológico. É por isso que Heidegger (2015, p. 108) chega a dizer que "no interior da maquinação não há nada digno de questão, algo tal que pudesse ser honrado enquanto tal [...] e, com isso, iluminado e elevado ao nível da verdade".

O fato é que maquinação é vivência e vivência é maquinação, âmbito no qual se mantém a publicidade disposta à totalidade, aquela curiosidade estimulante que excita e encanta os sujeitos em dimensão global. Nessa era de desenraizamento de questões, a solicitude para a solidão é aniquilada. $O$ debandar da funcionalidade maquinal para as vivências curiosas e interessantes não nos direciona à superação do enfeitiçamento do fazer e do poder. Mas

[...] é importante saber que aqui, em todo o deserto e em todo o caráter terrível, ressoa algo da essência do seer e alvorece o abandono do ente (enquanto maquinação e vivência) pelo seer. Essa era da completa ausência de questão só pode ser ultrapassada por uma era da simples solidão, na qual se prepara a prontidão para a verdade do próprio seer (HEIDEGGER, 2015, p. 109).

Mesmo onde a atividade da maquinação impera, é nela onde o seer se dá, clareando o ente de sua indigência (finitude) enquanto aquele que está ingresso no fazer e no feito das vivências. A ausência de questão só pode ser ultrapassada porque, de fato, ela impera nos tempos hodiernos. Nesse sentido, a desertificação maquinal, promotora da carência de indigência (ausência de consciência de finitude), não é de todo terrível, pois é ela que traz à tona as condições, a situação fático-histórica para um novo pensar, abrindo espaço a outro modo de pensar a história e o seer.

A maquinação surge a partir do abandono do ser (Seinsverlassenheit), que acontece de forma intensa onde há o seu velamento de maneira mais profunda. Isso se dá no ente, que se tornou o mais habitual, já que tudo a ele é possível e habitado. o Cristianismo é símbolo disso a partir de sua dogmática segundo a qual o ente humano é salientado, "originariamente", como ens creatum e o seu criador é tido como o mais evidente e certo, bem como todos os entes se manifestam como efeito desse fundamento. $\mathrm{O}$ Cristianismo, em suas explicações sobre a origem, toma como auxílio a clareza no calculável e naquilo que é comum e habitual. Se o ente é o mais habitual, o seer é o que há de mais inabitual, já que se dá de modo oculto, o que o faz ser esquecido e recusado. Ele se subtraiu inteiramente e abandonou o ente. Que o seer abandona o ente significa dizer que se vela nas manifestações representativas do ente. "Então, é no ocultamento do ser que devem ser procuradas as verdadeiras razões da situação histórica da humanidade atual, que Heidegger descreve na forma de um desenraizamento da facticidade humana da verdade do ser" (RAMOS, 2015, 
p. 274). Ou seja, se a facticidade do homem se instalou na ausência de indigência (na factibilidade maquinal), trata-se do próprio ocultamento do seer se dando na nossa era.

As manifestações representativas que promovem a maquinação se iniciam já no mundo grego como vimos de modo resumido. Na seção 61 das Contribuições à Filosofia, Heidegger diz:

\begin{abstract}
A questão é que, no tempo do primeiro início, uma vez que se chega à despotencialização da $\varphi v ́ \sigma ı \zeta$, a maquinação ainda não vem à tona em sua plena essência. Ela permanece encoberta na presentidade constante, cuja determinação alcança na $\dot{v} \nu \tau \varepsilon \lambda \varepsilon ́ \chi \varepsilon ı \alpha$ o aguçamento máximo no interior do pensar grego inicial. $O$ conceito medieval de actus encobre já a essência inicialmente grega da interpretação da entidade. Está em conexão, com isso, o fato de que, então, o elemento maquinal se impõe mais claramente e, por meio da inserção em jogo da ideia judaico-cristã da criação e da representação correspondente de Deus, o ens se transforma em ens

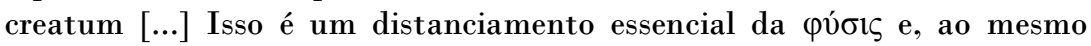
tempo, a passagem para o vir à tona da maquinação como a essência da entidade no pensamento moderno (HEIDEGGER, 2015, p. 125).
\end{abstract}

A maquinação não é um produto essencialmente grego. Na Grécia ela se inicia. Durante os períodos históricos, a maquinação vai sendo modulada, perpassando a entelékheia, o conceito de actus, a concepção de Deus, até culminar no pensamento moderno do ego calculante. A grande questão é que todas essas formas de maquinação historicamente dadas advêm da própria essenciação do seer e, ao mesmo tempo, da subtração dessa essência. Trata-se da duplicidade da sua vigência: acontecimento apropriador (Ereignis) como des-apropriação (Ent-eignis).

A essência maquinal do ente é complexa de ser definida historicamente porque começa a se efetivar desde o primeiro princípio ${ }^{4}$ do pensar ocidental, mais claramente a partir da queda da alétheia. Assim, a maquinação já é vista, na concepção heideggeriana, na téchne e na kínesis, que promovem alterações a partir das quais o ente ganha presença. Mas por que a téchne se encontra na instância da maquinação? Segundo Heidegger (1977, p. 61, grifos do autor), na conferência $A$ origem da obra de arte de 1935: “A $\tau \dot{\chi} \chi v \eta$, enquanto saber de modo grego, é, nessa medida, um produzir do ente, enquanto traz aquilo que está presente enquanto tal para fora do estar-encoberto precisamente para o não-estar-encoberto". A maquinação aqui se dá, posto que a vontade de poder é a sua força para desencobrir o ente e modular a natureza. Todavia, a téchne no pensar grego, antes de sua queda, ressalta e exalta o caráter de desvelamento da physis, acolhendo as suas revelações. É a partir de Platão que a téchne passa a perder a sua vigência de recepção e, na técnica moderna, o seu caráter acolhedor das sugestões da natureza não tem mais espaço, pois os dispositivos calculantes buscam explorar o real.

A maquinação está na dimensão da vivência e vemos a copertinência entre elas. Ambas andam juntas no cálculo do mundo. Elas se arrogam absolutas e perenes, sendo, dessa forma, louvado o perfeitamente factível. A maquinação e a

\footnotetext{
${ }^{4} \mathrm{O}$ primeiro princípio significa a era do esquecimento do ser, que se inicia entre os gregos quando o caráter de alétheia da physis sofre a queda para a correção na filosofia platônica. O primeiro princípio perpassa todas as épocas ocidentais, inclusive a contemporaneidade.
} 
vivência representam a história da verdade e da entidade e, assim, há o abandono do ente por toda verdade vigencial do seer. Mas o abandono, esse momento do acontecimento apropriador seria mal compreendido se fosse interpretado como um processo de decadência, o que não é em hipótese alguma. O que se dá é o seer perpassando as próprias descobertas do ente e de suas objetivações em um determinado período. Ilusoriamente o ente se encontra carente de pano de fundo ou de fundamento originário-fenomenológico. As "criações" maquinais têm o seu aparecimento "natural" segundo o ente, que se instauram "desprovidas" de acontecimento originário. Para a subjetividade, as coisas advêm e se encontram no próprio entitativo como se não existisse um fundo anterior a toda essa constituição.

O elemento "natural", nos tempos coevos, não tem mais relação com a physis que despontava por si mesma entre os gregos originários, mas está colocado inteiramente na dimensão do maquinal. O "natural" é o factível, o determinável, o calculável, o vivenciável que se exaure nas suas próprias riquezas e cai, cada vez mais, na desertificação do mundo, já que os seus recursos são apenas disponíveis para o natural e não prontos para o cuidado (Sorge $)^{5}$. Dessa forma, se o que impera nos tempos hodiernos é a funcionalidade técnica, o ente não se mostra solícito à abertura do fundamento (Seyn) e, por isso, o abandono do ente passa a ser inevitável.

Mas, de fato, o que é o abandono do ente? É justamente o fato de o seer ter se retraído à dimensão ôntica e esta, no Cristianismo, ter se transmutado em ens creatum (efeito) de uma causa fundamental (outro ente, mas divinizado). O Cristianismo surge pari passu com a instância da técnica, uma vez que entende o ente como uma criação e esta criação como uma realização, um feito de uma causa eficiente. Nessa visão, o ente é entendido como aquele que poder fazer (machen) constantemente. Essa factibilidade do poder (Macht) propicia a maquinação (Machenschaft). A entidade suprema, como causa essencial, assume a essência do seer. Assim, o abandono do seer se dá pelo fato de

[...] o seer abandonar o ente, entregando-o a si mesmo e deixando-o se transformar no objeto da maquinação. Tudo isso não é simplesmente "decadência", mas é a primeira história do próprio seer, a história do primeiro início, do que é dele derivado e do que fica necessariamente para trás. Mas mesmo esse ficar para trás não é nenhum mero "negativo". Ao contrário, ele traz à tona, em seu fim, pela primeira vez, o abandono do ser (HEIDEGGER, 2015, p. 110).

Vê-se que "cair" na instância do maquinal-objetual não é "opção" do ente e sim uma entrega do homem a si mesmo, entrega essa que o faz produto da maquinação. Esse fato histórico não indica sua falta ou irresponsabilidade, mas a história do primeiro princípio do pensar como esquecimento do ser. Junto a esse esquecimento, há o abandono do seer que instaura o duplo caráter de Gegenüber. Gegen, na língua alemã, é uma proposição que rege o acusativo e indica "contra", "contraposição". Gegenüber significa "diante-de", "estar defronte", como aquele que está "além do contra". Assim, ser-aí (Dasein) é o ente que está contraposto ao seer pela profunda diferença ontológica existente entre ambos. Ao mesmo tempo, ser-aí

\footnotetext{
5 Sorge compreendida como a solicitude ao mistério do ser. O cuidado é própria insistência do ser-aí em ser o
} acolhedor do sublime que se dá a cada época e que estrutura contextos históricos. 
está diante do originário para ser apropriado por ele. É no interior desse paralelismo entre as duas instâncias (contraposto e diante-de) que distintas determinações epocais e estruturações históricas se dão. Nesse sentido, reflete Trawny:

A filosofia de Heidegger [...] anseia pela intiminade. Busca um diante-de (Gegenüber) que não coloque empecilhos para o inacessível, que esteja aberto para introduzir-se no propriamente intransponível; um diante-de que concorda com o pensamento de que a questão do pensar é o inacessível (TRAWNY, 2013, n.p.).

O que as meditações heideggerianas deixam transparecer é a abertura à intimidade com a verdade do seer. Aqui se demonstra que o seer abandona o ente, velando-se na manifestação ôntica. $O$ essenciar-se do seer é determinado quando este se retrai em seu desencobrimento. Essa "saída" é o que abandona o ente e o deixa fixo na maquinação. $O$ originário (Seyn) o abandona na medida em que o princípio grego da alétheia deixa de ser o fundamental que se retrai do ente, prenunciando a adequação da entidade ao eidos. A entidade do ente vige meramente como um adendo, já que a realidade primeva e originária é próteron, o a priori como aspecto platônico. Há, dessa forma, a despotencialização da physis. Na metafísica platônica, a entidade necessita se tornar o que existe de mais inteligível e o que há de mais certo e evidente. Esse abandono do ser necessita ser experimentado como a indigência a partir do acontecimento apropriador fundamental (Seyn) da história do Ocidente para, a partir dele, surgir a transição como aceno e acesso ao porvir: um futuro de lembrança da verdade do seer.

$O$ "progresso" não experimenta o porvir. Não há sentido essencial na noção de "progresso", já que isso é uma construção maquinal, que fomenta o que até o momento se deu: o caminho das valorações vivenciais. O "progresso" espera em expectativa, já o porvir é nadificador, uma vinda que passa ao largo do que o homem deseja e estabelece como meta. Assim, "O que nos compele, o que se mantém sem ser captado excede essencialmente todo e qualquer 'progresso' porque se trata do autêntico futuro mesmo, de tal modo que ele escapa, em geral, da diferença entre o mal e o bem e se subtrai a todo cálculo" (HEIDEGGER, 2015, p. 111). A indicação mais forte do abandono do ser é a própria volição da massa humana que se esbalda no estrondo do desmedido a ponto de sofrer a indigência da carência de indigência (die Not der Notlosigkeit), isto é, a falta de consciência de sua finitude. Essa culminação é inessencial, já que fecha o ente para as possibilidades abertas do seer, não percebendo a sua indigência frente ao fundamento (Seyn). Faz-se mister uma indigência (assunção de finitude) que possa compelir o homem à luz do dia, que o tire da aquietação da aparência do fazer cultural. É preciso acolher a transição na sua mais íntima experiência enquanto aceno da mensagem essencial.

Mesmo em nossa época, cujo o aceno está se dando no pensamento de Heidegger, o esquecimento do ser ainda permanece. $O$ valor se dá pelo estar junto ao ente, unido ao efetivamente real, à clarividência da vida e de suas vivências produtivas. É justamente essa presentação entitativa, esse ente que é abandonado pelo seer. Esse abandono gera à consciência do ente a imaginária aparência de autonomia e ausência de qualquer necessidade de uma alteridade originária. "O abandono do seer, contudo, é o ser exposto e a proibição do acontecimento 
apropriador" (HEIDEGGER, 2015, p. 113). É a partir do abandono do seer que se faz necessária a ressonância do fundamento originário para acontecer o soar do seer no ente.

Vimos, nas meditações de Heidegger a respeito da história do pensamento que o ente, abandonado pelo seer, é pertencente a essa vigência. Nesse abandono, o ente, instalando-se na indigência da carência de indigência (ausência de consciência de finitude), passa a ser indiferente, impertinente e arbitrário em relação ao que o funda, pois tudo é presença à vista. No abandono do seer, a essência é perturbada, ganhando a verdade como correção da representação no aspecto. Nesse abandono, há o esquecimento do ser a partir de uma compreensão de ser dominante consumado como universalidade, aquilo que há de mais geral (koinón). Aqui, o principial não é experimentado enquanto tal, mas é entendido a partir da questão diretriz (Leitfrage) do ente, já que é concebido como o uno-tudo fundante do real. Trata-se de um desenraizamento histórico fundado na própria essência do seer que se subtrai ao ente, deixando-o aparecer com sendo e, além disso, como sendo mais. $\mathrm{O}$ ente aparece, nesse percurso, como um carente de seer (Seynlose), uma vez que sua efetividade se instaura como a fundadora do real e, a partir desse império do fazer ôntico, o homem passa a ter carência de seer (Seynlosigkeit).

Heidegger apresenta a seção 56 das Contribuições, onde anuncia o abandono do ser a partir dos seguintes acontecimentos: 1. a inteira insensibilidade em relação ao que é essencial, a má vontade em relação à decisão pelo fundamento real, que leva o povo $^{6}$ a estabelecer definições para raça, grau hierárquico e a permanência do estável: o divino; 2 a confusão ontológica em não saber o que é condicionante e o que é condicionado; 3. a permanência nos valores e ideias, isto é, o pensamento preso às visões de mundo, inseridas nas instituições e nas engrenagens culturais; 4. a apequenação e o desprezo da ausência fundamental (Seyn). Isso demonstra a longa distância e o não saber relativo ao pertencimento do homem à nulidade do seer, que aprofundam o ente na aparência da vontade maximizada e o fazem fugir da meditação a respeito dos elementos maquinais; 5 . o silêncio, a tranquilidade e a retenção são tidos como meras inatividades e como renúncia à vida; 6 . a petrificação no cálculo em contraposição aos acenos do mistério; 7 . o velamento do desenraizamento calcificado pelas descobertas, invenções, fábricas e máquinas; a massificação do homem e a negligência com o fundamento. $O$ desenraizamento aparece como o mais profundo velamento da indigência, porque produz a desertificação da realidade (esquecimento do fundamento), já que tudo tem que proporcionar rapidez e definições exatas, o que promove a violência do ente a partir de suas criações e de suas instituições.

Na era da técnica, fundada no conhecimento matematizável, não há o impossível, visto que o ente possui certeza (Gewissheit). Não se precisa indagar sobre

\footnotetext{
6 “Volk corresponde aproximadamente, mas não exatamente, a 'um/o povo', [...] a 'massa do povo' [...] O velho adjetivo völkisch significava, originalmente, o mesmo que o tardio vokstümlisch, 'pertencente a, em harmonia com, o povo, popular'. Mais tarde passou a ter o sentido de 'nacional', sendo usado pelos nazistas neste sentido com o acréscimo da conotação 'popular' e 'racial'. Com as suas sugestões de 'folclore' racial, 'nação' e 'povo comum', Volk servia à combinação nazista de nacionalismo autoritário com um igualitarismo democrático [...] Tal utilização demonstra 'a insensibilidade à ambiguidade' que Heidegger considera um sintoma do 'abandono pelo ser" (INWOOD, 2002, p. 149). Por que Volk representa tal abandono? Segundo Heidegger, o povo, como primado, instaura o niilismo, de modo que se regula a fim de eliminar a falta de objetivos essenciais do ser humano, caminhando na instância da maquinação.
}

BRANCO, Rodrigo Amorim Castelo. A maquinação a partir do abandono e do esquecimento do ser em Heidegger. Griot : Revista de Filosofia, Amargosa - BA, v.19, n.2, p.22-40, junho, 2019. 
a essência da verdade, porque a verdade é o próprio cálculo. No entanto, e o elemento incalculável, está sob o poder do ente? Sim, ele só é incalculável, pois a técnica não chegou até o elemento para determiná-lo. A rapidez (Die Schnelligkeit) das velocidades técnicas e o surgimento do massivo (Der Aufbruch des Massenhaften) ("o acessível a qualquer um da mesma maneira") são responsáveis pelo encobrimento do abandono do ser. "Todos esses sinais do abandono do ser apontam para o começo da era da completa ausência de questão de todas as coisas e de todas as maquinações" (HEIDEGGER, 2015, p. 122). Não se admite nenhum velamento essencial e, além disso, talvez o essenciar-se do primordial não se dê no solo do ente.

O parecer de Ortega y Gasset acerca do massivo nos traz uma boa reflexão a respeito do cálculo maquinal:

\footnotetext{
O mundo que desde o nascimento rodeia o homem novo não o move a limitar-se em nenhum sentido, não lhe apresenta veto nem contenção alguma, mas, pelo contrário, fustiga seus apetites, que, em princípio, podem crescer indefinidamente. Pois acontece [...] que esse mundo do século XIX e começos do XX não tem apenas as perfeições e amplitudes que de fato possui, mas que além disso, sugere a seus habitantes uma segurança radical em que amanhã será ainda mais rico, mais perfeito e mais amplo (ORTEGA Y GASSET, 2001, p. 177).
}

O massivo não deixa transparecer limites. A rapidez deve imperar sem qualquer obstrução que leve a técnica a reduzir o seu poder ou deixar o seu fazer constante. Surge a crença maquinal na segurança (Sicherheit), que estimula não só a ciência especializada, mas o massivo a acreditar no asseguramento (Sicherung) do futuro, que a exploração da terra trará mais opulência e amplitude nas relações comerciais, políticas e sociais. Não havendo qualquer forma de veto ao cálculo do ente, tudo pode ser domado.

Hoje, a era da civilização se identifica com a era do desencantamento com o originário (Seyn) pari passu com a ausência de questão. No entanto, em relação ao domínio ilimitado da maquinação, o encantamento é estremecedor. A partir da regulação da técnica, há nivelação. A medianidade, a cada vez, torna-se surpreendente em virtude do melhoramento maquinal. É falso e, por conseguinte, enganador achar que essa elevação do nivelamento da medianidade gera uma significativa realização acima da média. Segundo Heidegger, essa resolução é apenas um sinal da determinação calculante da Modernidade. Essa insistente elevação do nível do mediano é a essência mesma de toda funcionalidade, que promove a aniquilação dos sítios de decisão.

\section{A maquinação e o gigantesco}

O gigantesco (das Riesenhafte) parte do que há de mais próximo e imediato, aquilo que está presente à vista, que deixa ecoar em maior grau o abandono do ser no qual a história hodierna se instalou, demonstrando a soberania da inessência da physis no nível elevado de maquinação (Machenschaft). Mas, de fato, o que principia a maquinação? Segundo Ramos: 
Quando o abandono e o esquecimento do ser não são concebidos como um acontecimento da verdade do ser, isto é, não são propriamente sustentados na existência humana mediante o saber criativo que custodia a recusa do ser, o sentido de existir em meio ao ente passa a se orientar pela maquinação e dominado pelo privilégio das vivências [...] Nesse sentido, a maquinação é a determinação da entidade do ente abandonado pelo ser (RAMOS, 2015, p. 278).

O abandono e o esquecimento do seer, originalmente, se dão pelo seer mesmo. Quando o homem se retira da posição de custódio do primordial (Seyn), ingressa no mundo na maquinação e do vitalismo, uma vez que as vivências emergem como fundadoras e exploradoras do real. Todavia, é o ir embora do seer o que faz chegar o domínio maquinal ao escopo do ente. Não obstante, deve-se ficar claro que a maquinação não é um produto originário do fazer humano, mas é, antes de qualquer assimilação ôntica, o advento, no Ocidente, que parte da verdade (essenciação) da clareira (Seyn).

A maquinação, hoje, apresenta-se como gigantesco, isto é, "não se mostra mais como o elemento objetual re-presentável de algo 'quantitativo' ilimitado, mas a quantidade é que se revela como qualidade" (HEIDEGGER, 2015, p. 133). Nos nossos tempos, o gigantesco representa a profunda inessência do seer, uma vez que é posto como produto da entidade do ente e como factibilidade presente. Isso indica alto grau de carência, que é a indigência da falta de indigência (ausência de consciência de finitude), proeza esta do gigantesco que transmuta o quantitativo em qualitativo. "Essa 'transformação' é preparada pelo fato de que a entidade é

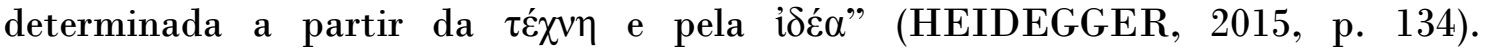
Compreendemos, assim, que o gigantesco de hoje já se prenuncia na metafísica grega.

No gigantesco surge o re-presentar sistemático, que busca se assegurar no imperativo fundamental da determinação do objeto. A lei é antecipar, planejar e instituir não encontrando limites, dado que a finalidade e o decisivo é o calculável e o incalculável. Tudo é possível de ser apreendido e manipulável. $\mathrm{O}$ gigantesco não conhece o impossível e até mesmo chega a refutar esse vocábulo, já que tudo é onticamente possível, levando-se em conta que a realidade seja calculada e, por conseguinte, humanamente produzida. $O$ cálculo é a essência do quantitativo e o fundo basilar do gigantesco. É desse modo que há o abandono do ser do ente enquanto tal, nessa dissimulação que faz do ente aquilo que há de mais vigente e estabelecido como fundamento, evidencia Heidegger.

O quantitativo se tornando qualidade atesta a inessência do seer, que vem por meio da sua própria essência quando ele se apropria do ente. A inessência aqui é do ente apropriado (indigência da falta de indigência), que se dá a partir do essenciar-se do acontecimento apropriador (Seyn). O re-presentar do gigantesco, no qual a essência do quantitativo é realizada, mantém-se concluso no ente e o trancafia em contraposição ao seer ou, no máximo, só deixa este último "viger" de forma representativa como um vazio não significativo. $O$ gigantesco é a virada das costas para o fundamento que o originou, todavia, ele não pode se tornar a sua própria origem, daí a impotência (Ohnmacht) deste poder. Como salienta Heidegger (2015, p. 135): "Antes de tudo, porém, concebido historicamente, o gigantesco enquanto tal é o incalculável. Esse elemento incalculável, contudo, é o anúncio intangível, que vem da proximidade superpróxima do seer mesmo, mas sob a figura da ausência de 
indigência da indigência". $O$ "abismal" é que a condição instaurada pelo domínio do gigantesco advém da própria retração do seer.

$O$ gigantesco desconhece toda e qualquer falta porque, para ele, não há ausência ou não possibilidade do fazer, do ter e do realizar. Surge a aparência de tudo possuir. Não há o inesgotável, já que o real pode ser explorado. Ele não conhece o que é simples, dirigindo-se sempre à complexidade do cálculo da vida, assim a simplicidade se vela para ele. Aliás, até mesmo essa simplicidade está por ele dominada. No entanto, enquanto recusa do simples (seer), é justamente essa recusa que permite anunciá-lo.

O agir do gigantesco é o que dá espaço para o niilismo. Heidegger demonstra que no sentido nietzscheano, niilismo indica que as metas não existem mais. Mas tendo em vista o pensamento heideggeriano, o niilismo precisa ser concebido de forma originária como decorrência do abandono do seer. O fato é que a constatação do niilismo de Nietzsche sobre a ausência de metas não impeliu os seus contemporâneos a uma meditação profunda, mas antes negaram essa verdade como algo nulo e incorreto, não se admitindo a ausência de metas. Dessa forma, distintas e diversas metas são traçadas e divulgadas como o motivo principal do bem-estar. Os bens culturais são estabelecidos como os bens massivos. É nessa vivência barulhenta na qual se encontra o maior e o mais profundo niilismo, posto que a calmaria do silêncio é sobrepujada em privilégio da decisão que estabelece metas cotidianas e rotineiras. Isso indica o temor do homem: "O medo diante do seer nunca foi tão grande quanto hoje. Prova: a instituição gigantesca para que o grito ofusque esse temor [...] Não se quer reconhecer como o âmbito de decisão sobre o seer" (HEIDEGGER, 2015, p. 137). O temor perante o retraimento do mistério faz com que o gigantesco tenha como escopo qualificar a quantidade como a essência do bemestar.

A questão é que o homem não precisa temer o abandono do seer dado que já foi abandonado pelo fundamento. Nesse abandono, o ente foi entregue à maquinação e às vivências, explicita Heidegger. Na tentativa de salvar a cultura e a sua política, o Ocidente cai no niilismo com a sua metafísica, já que a diversidade de metas se dão para suprir o vazio do fim do primeiro princípio. A noção de "progresso" toma o seu lugar, por exemplo, com a Aufklärung (Esclarecimento). A superação desse niilismo só se dará a partir do momento em que o saber primordial da recusa no seu acontecimento apropriador (Seyn) se der na experiência fundamental do ente, abrindo-se ao ser-aí. E esse saber advém do próprio abandono do ser.

\section{A maquinação e o gigantesco na ciência}

Heidegger indica que a ciência (Wissenschaft) moderna e contemporânea não tem a capacidade de ingressar na instância de decisão sobre a essência do seer. Mas por qual motivo? Ela está profundamente enraizada na dimensão maquinal-objetual do gigantesco. A ciência assume a figura da certeza e da correção (Richtigkeit), pensando o ente (sujeito) como aquilo que está contraposto ao representado (objeto). Aqui, vê-se que há o abandono do ser na ciência moderna, já que a retenção da alétheia é coagida e reprimida em meio ao esquecimento da eclosão originária da

BRANCO, Rodrigo Amorim Castelo. A maquinação a partir do abandono e do esquecimento do ser em Heidegger. Griot : Revista de Filosofia, Amargosa - BA, v.19, n.2, p.22-40, junho, 2019. 
physis. Surge a força do saber representativo-normativo da ciência como pensar calculante. Dessa forma,

\begin{abstract}
É acentuado, então, que, em razão da essência das ciências serem um arranjamento que erige um saber por um contexto de correções (verdade como Richtigkeit), portanto, por faltar a elas um genuíno saber histórico e criativo-transformador da verdade do ser, é inevitável às ciências se afirmarem como um saber maquinador. De acordo com tal meditação, essa essência maquinadora seria reconhecível, sobretudo, no fato que seu método e sua específica exigência de rigor e exatidão conduzem a atestar a necessidade de si mesmas somente por meio de uma crescente obtenção de resultados, portanto, não pela experiência de uma constrição gerada na ausência da verdade do ser (RAMOS, 2015, p. 276).
\end{abstract}

Como se vê na indicação, as ciências estão em um contexto de "autonomia" do ente, que não se ergue a partir do respaldo da verdade originária (verdade do seer). A atividade científica, pautada na instituição do método e do sistema no emaranhado de induções, deduções e experimentos diversos, permanece na busca incessante de êxitos. Essa era já se prenuncia desde a queda da alétheia com as fundamentações metafísicas da filosofia, que instaura a era da epistemologia. No entanto, é preciso haver uma meditação sobre essa ciência e a respeito de sua essência maquinal para se ver o aceno do abandono do ser como um ecoar do seer.

$O$ fato é que a ciência não alcança, em qualquer momento, o campo de decisão sobre a verdade do seer, porque assume a figura da certeza que se afirma sob a forma do pensar moderno e contemporâneo, que se instala como um recorte lógico-racional do conhecimento, pretendendo ser o ponto central do saber normativo. É por este motivo que a meditação sobre a ciência e sobre a sua essência maquinal hoje tão enraizada é a preparação para a travessia a um outro pensar que tenta abrir espaço para a compreensão (Verständnis) do abandono do ser como o próprio soar do seer.

Segundo Heidegger, para a filosofia se mover nessa transição à lembrança da verdade do seer, todo tipo de insistência na fundamentação científico-teórica não dota mais sentido e se torna inaceitável para um outro limiar histórico, isso porque essas teorizações tornam a ciência como aquilo que está presente à vista, passando ao largo de uma consistência essencial a partir do fundamento nulo (Seyn). Nesse sentido, metas do povo, relações políticas, concepções antropológicas e toda empreitada metafísica da história do Ocidente são insuficientes, porque faltam a elas a meditação fenomenologicamente necessária.

Nos tempos coevos vivemos uma crescente particularização das áreas do saber e presenciamos a caracterização da essência da ciência promovida pelo ente nas suas grandes distinções entre ciências históricas como ciências do espírito (Geisteswissenschaften) e ciências exatas unidas às ciências da natureza (Naturwissenschaften). Para Heidegger, esse agrupamento de ciências apenas encobre a precariedade de sua essência, porque de toda forma, nelas o abandono do ser permanece, bem como a ausência da verdade de toda ciência. O que há é a mobilização extremada de procedimentos, instituições e técnicas para dividir as ciências e estabelecê-las a partir da "criatividade" do primado do ente.

Heidegger apresenta, na seção 76 das Contribuições à Filosofia, as "Sentenças sobre a "ciência" (Sätze über die "Wissenschaft"). Para o filósofo, a ciência precisa ser 
analisada em seu sentido moderno. Embora a epistéme e o pensamento medieval façam parte da determinação da ciência ao modo como a conhecemos hoje, trazendo a noção de correção do aspecto e adaequatio, é na Modernidade que a verdade como cálculo se instaura. Em sentido de uma verdade originária e essencial, a ciência moderna não indica nenhum saber, pois a verdade se consuma nela mesma. Contudo, a ciência é uma instância que deriva de um fundamento anterior. A sua maquinação não é produto de si mesma, a sua esfera de correções parte do interior de uma região fundamental sempre em constrição, que, por estar ao largo da ciência, por ela permanece inquestionado.

A ciência é vista como um positum ${ }^{7}$ por Heidegger, isto é, positiva, porque nela a verdade é posta pela metodologia observacional do ente com o auxílio de recursos lógico-matemáticos. A ciência positiva, a cada período, mais se particulariza para poder tanto mais calcular. Trata-se de uma maximização da especialização que

\begin{abstract}
não é, por exemplo, um fenômeno de decadência e de denegação 'da' ciência, nem tampouco apenas um mal inevitável enquanto consequência do progresso e da inabarcabilidade da divisão do trabalho, mas uma consequência interna necessária de seu caráter enquanto ciência particular e uma condição inalienável de sua consistência, isto é, sempre de seu progresso (HEIDEGGER, 2015, p. 143).
\end{abstract}

A especialização constante das ciências não é vista por Heidegger como algo nocivo ou como uma queda, mas uma precisão da ciência de se particularizar para o melhor ingresso nos seus objetos de estudo a ponto de lograr êxito com rapidez e dinamicidade. A questão é como a ciência o faz. As coisas passam a ser explicadas tão onticamente, que as análises da vida e de suas feituras são realizadas a partir do aspecto físico-químico, da objetividade fisiológica-psicológica. Essa é a consequência interna de sua necessidade. "Cada ciência é do modo como ela "positivamente" precisa [...] se singularizar a partir da respectiva perspectiva com vistas a uma região cada vez própria" (HEIDEGGER, 2015, p. 144).

Como a atividade científica é norteada por um caminho metodológico, aqui residindo o seu rigor, modos de avanço, execução e investigação do objeto em questão, a pesquisa científica, de antemão, já direciona as suas análises sobre o objeto de estudo para o interior definido da explicabilidade, assegurando-se de uma certeza, tornando inevitável não atingir um determinado resultado já esperado. Aqui fica claro o desconhecimento da essência, a falta do fundamento originário, o desconhecimento de que há uma abertura que se vela (Seyn). Isso acontece visto que, para a ciência, tudo é factível, explicativo e resolutivo.

$\mathrm{O}$ asseguramento do resultado previsto representa o modelo do procedimento científico, cujo o escopo é a disposição para prever séries e cadeias particulares, encontrando a relação entre causa e efeito das coisas. Não é isso que o método indutivo-dedutivo almeja? Isto é, por meio de condições observacionais particulares, generalizar resultados como leis totalizantes para todos os outros fenômenos que se dão? O pensamento seguro pautado na causalidade da ciência se apoia nas ligações "se-então" (wenn-dann) sob o modo do "quando-então" (wann-dann). Se um

\footnotetext{
${ }^{7}$ Cfr. HEIDEGGER, Martin. 76. Sentenças sobre a "ciência". In: Contribuições à filosofia (Do acontecimento
} apropriador). Rio de Janeiro: Via Verita, 2015, p. 143.

BRANCO, Rodrigo Amorim Castelo. A maquinação a partir do abandono e do esquecimento do ser em Heidegger. Griot : Revista de Filosofia, Amargosa - BA, v.19, n.2, p.22-40, junho, 2019. 
determinado evento se deu tal como ocorreu no passado, então o mesmo efeito surgirá no presente. Trata-se de um raciocínio empírico (empeiría) por previsão (tomada de conhecimento de seus objetos de estudo por meio da experiência e do experimentum), que tende a ver o futuro como uma mera repetição do passado e que, por isso, todo e qualquer resultado científico está no âmbito da explicabilidade, uma vez que a factibilidade (Machbarkeit) do método da ciência espera o resultado em seu plano de certeza. Aqui, o experimento é a condição necessária para a essência da exatidão e a ciência aparece como exata, porque parte dos dados do próprio experimento $^{8}$.

Em Platão: o sofista de 1924-25, Heidegger faz uma leitura da empeiría, levando em consideração a abordagem aristotélica do termo. $O$ pensador alemão diz

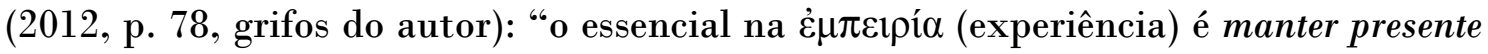
um contexto determinado de ocorrências na mesma coisa [...] Não se compreende senão uma conexão, que precisamos caracterizar como conexão própria à presença de determinadas ocorrências. No devir temporal, essa conexão apresentada pode se estabelecer e se transformar em empeiría. A conexão citada por Heidegger quer dizer o logo que-então. Trata-se de uma conexão de ocorrências, que visa promover a conexão de atualização ${ }^{9}$, isto é, logo que uma primeira ocorrência se fizer presente, então uma outra se dará, gerando um coestabelecimento de eventos (logo que um acontecimento (causa), então outro evento ocorrerá (efeito)). Nota-se que por essa orientação do ente humano os eventos temporais são regidos pela causalidade, porque os acontecimentos vão se dando, precisamente, como devem ser. Desse modo, a percepção sensível (aisthesis) se respalda, seguramente, na experiência, já que a conexão estabelecida se torna uma conexão determinada e "segura". Por meio da causalidade sensorial, a experiência passa a construir as suas hipóteses por meio do logo que isso..., então isso.

Apesar de todo estabelecimento factual dado pela empeiría, o ser-aí "continua sem nenhuma intelecção na conexão como tal [...] Trata-se, aqui, de uma atualização totalmente primitiva" (HEIDEGGER, 2012, p. 79). Na verdade, a conexão causal da experiência logo que..., então, mostra-se não como completude de um evento (entelékheia), mas como disposição para (dynamis), isto é, como um mero erigir inicial do que se dá, "um primeiro estar colocado em relação a...". Todavia, o ser-aí pensa ter encontrado, na pluralidade de percepções sensíveis, que se apresenta na experiência (empeiría), a unidade segura por meio da conexão material-causal. A esse respeito, salienta Heidegger:

\footnotetext{
Ante a conexão puramente temporal, descobre-se o quid respectivo. "O

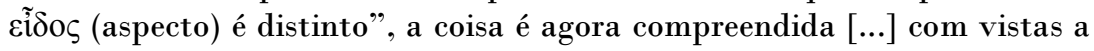
um aspecto que se mantém, que retoma constantemente. Com isso,

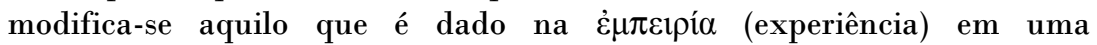
compreensão totalmente provisória: o logo que - então transforma-se no se isso - então isso, no se - então. Esse "se" tem, de início, um significado totalmente estranho, indiferente: ele não significa mais apenas um mero
}

\footnotetext{
${ }^{8}$ Sobre a questão do método indutivo, cfr. POPPER, Karl. Colocação de alguns problemas fundamentais. In: $A$ lógica da pesquisa científica. São Paulo: Cultrix, 2013, pp. 27-46.

9 Cfr. HEIDEGGER, Martin. Platão: o sofista. Rio de Janeiro: Forense Universitária, 2012, p. 79.
} 
"logo que", mas também já um certo "porque (HEIDEGGER, 2012, p. 81).

Agora se explica por que as conexões meramente empíricas instauram conexões materiais-causais que não promovem intelecção. De todo modo, esse nexo causal não atinge o essencial, isto é, o aspecto conceitual daquilo que se apresenta por meio da experiência. Faz-se mister passar do nível da aisthesis, do logo que - então à instância do se - então, dimensão na qual, respaldada pelo aspecto, explica-se o porquê dos fenômenos que se mostram de modo ordenado. A compreensão, desse modo, torna-se mais clara e própria à medida em que o eidos do que se apresenta passa a ser destacado e considerado em sua essência, além de meras relações materiais em sua dimensão de causa e efeito. Nesse itinerário formal, a compreensão não se erige, fundamentalmente, com base no solo das ocorrências e das sequências empíricas ou por base das "atualizações" causais, mas a intelecção do ente se dá por meio da evidência do aspecto que se apresenta no ente. "Por isso, dizemos que aquele

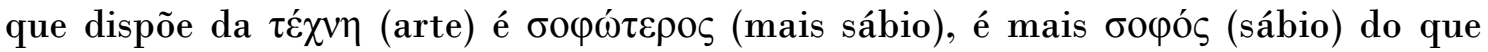
aquele que apenas dispõe sobre a $\dot{\varepsilon} \mu \pi \varepsilon i p i ́ \alpha$ (experiência) (HEIDEGGER, 2012, p. 81). Essa nova possibilidade de enxergar o fenômeno que se apresenta não indica que a téchne vá realizá-lo, fazê-lo no lugar da própria natureza, mas o verá de forma mais significativa, em direção ao seu aspecto. O que está em jogo "reside no direcionamento do ver, não da realização. Esta permanece intocada" (HEIDEGGER, 2012, p. 82).

Retornando aos gregos, percebemos como a maquinação lá já se prenuncia. Por mais que a téchne não realize a natureza, é ela que a vê de forma mais completa, atingindo o seu aspecto. A arte científica, na Modernidade, adere a esse pensamento. Assim, eis o grande desenvolvimento da essência maquinal da técnica (machenschaftlichen-technischen) orientada para o transcurso fixado no autoevidente. Essa é a própria essência da ciência se demonstrando na medida em que aparece como a instituição da factibilidade, da certeza, no domínio do que é objetivo, disponível à utilização e à exploração. A diretriz aqui é o olhar para a instância dos resultados e, ao se reportar a estes, ela continua o seu processo de asseguramento, ratificando, a partir de si mesma, a necessidade de seus cálculos. Mas que necessidade é essa tão premente? Segundo a própria ciência, com a sua metodologia de rigor, ela se justifica como um dos mais altos valores culturais, estando a serviço popular para promover o progresso da vida. Aqui o primado do procedimento em face da correção do juízo promovida pela verdade do ente passa a ter várias finalidades, dentre elas, o bem-estar do povo perante as suas novas e curiosas "descobertas" que vai, cada vez mais, uniformizando-se na dimensão do factível e do calculável.

A ciência, como região explicativa do ente, a cada momento parte para novas finalidades conduzida por impulsos que tendem a prontificar a inexistência de qualquer ameaça. Heidegger, aqui, entende por ameaça o fundo essencial da ausência do seer que pode revelar ao ente o verdadeiro fundamento. Assim, a ciência, incapaz de refletir sobre a verdade do seer, não percebe os seus próprios limites, já que tudo é ser-factível (Machsamkeit).

A ciência tem como escopo abarcar a totalidade dos entes, já que a ausência elementar (Seyn) não lhe convém. Heidegger chega a afirmar que uma crise na ciência está distante, haja vista que ela age como uma fábrica do fazer constante, 
produzindo resoluções incessantemente, não dando espaço para a possibilidade de transformação essencial do saber e da verdade. Nesse sentido, a ciência é exata, significando aqui mensuradora, cuidadosa. Ela é exata no sentido do cuidado na manipulação dos seus métodos. "Exatidão" significa o próprio procedimento mensurador e calculador" (HEIDEGGER, 2015, p. 147), que não se abre ao aberto.

Heidegger afirma que a filosofia não é hostil à ciência, não sendo contra e nem a favor dela. $O$ que a filosofia faz é deixar a ciência entregue à sua própria busca utilitária, no prosseguimento a resultados cada vez mais utilizáveis, mais velozes e manuseáveis. Como na nossa era já chegamos ao reconhecimento da essência da ciência como funcionalidade e como colocamos esse funcionamento científico a nosso serviço - assim como o fizeram as várias instituições -, Heidegger compreende que podemos esperar por um grande "progresso" das ciências que, no entanto, trará consigo exploração da terra, domesticação do homem, situações estas ainda irrepresentáveis nos dias de hoje. Esses "progressos" se tornarão tão normais, serão realizações culturais consumidas massivamente e em série. Quando a ciência ingressar nesse gigantesco, desdobrando-se em sua funcionalidade e em seus resultados, haverá a dissolução de todo ente.

A técnica aqui referida é o normativo contemporâneo das produções do homem. Porém, a era da técnica é uma dis-posição, um desencobrimento que se dá na Modernidade e que se sobressai atualmente. Mas Heidegger perscruta, na conferência A questão da técnica de 1953:

\footnotetext{
Se o desencobrimento não for um simples feito do homem, onde é e como é que ele se dá e acontece? Não carece procurar muito longe. Basta perceber, sem preconceitos, o apelo que já sempre reivindica o homem, de maneira tão decisiva, que, somente neste apelo, ele pode vir a ser homem. Sempre que o homem abre olhos e ouvidos e desprende o coração, sempre que se entrega a pensar sentidos e a empenhar-se por propósitos, sempre que se solta em figuras e obras ou se esmera em pedidos e agradecimentos, ele se vê inserido no que já se lhe re-velou (HEIDEGGER, 2001, p. 22).
}

Como esclarece o trecho acerca da essência da técnica (maquinação), o desencobrimento que hoje se dá - o império da técnica e de suas funcionalidades não é uma realização meramente subjetiva. Antes de qualquer produção antropológica, há algo que promove apelo ao homem, que o solicita, reivindicando-o a ser-si-mesmo. $\mathrm{O}$ ser-si-mesmo acontece no acolhimento do que se desencobre e que, a partir disso, estrutura a época na qual estamos situados. A forma decisiva de desvelamento que acomete os homens vem à tona como elemento maquinal, que orienta o olhar, o ouvir, o sentir, o raciocinar, o empenhar-se dos entes em prol da maquinação do real. $O$ que cada um dos sujeitos faz é dar resposta à solicitação do desencobrimento, seja para aceitá-lo ou para refutá-lo. Sendo assim, ainda em $A$ questão da técnica, afirma Heidegger:

Quando, portanto, nas pesquisas e investigações o homem corre atrás da natureza, considerando-a um setor de sua representação, ele já se encontra comprometido com uma forma de desencobrimento. Trata-se do desencobrimento da técnica, que o desafia a explorar a natureza (HEIDEGGER, 2001, p. 22). 
Na atual fase da história da metafísica se dá a maquinação ou técnica (Machenschaft/Technik) $)^{10}$, que se apresenta, outrossim, como ciência. Ela empreende o maior asseguramento da certeza privado de sentido originário e, por isso, ingressa na completa ausência de questões. As coisas estão dadas à mão, os bens são realizáveis, os fins podem ser atingidos e as utilidades estão estabelecidas. A esse estímulo, "Chamamos, aqui, de com-posição $(G e \text {-stell })^{11}$, o apelo de exploração que reúne o homem a dis-por do que se des-encobre como dis-ponibilidade" (HEIDEGGER, 2001, p. 23). A tecnologia por si mesma não representa a essência da técnica. Ge-stell é a essência da própria técnica, como aquilo que abre a possibilidade para o homem caminhar no desmedido dos dispositivos calculantes. Ge-stell é o que requisita, desafia, provoca o ente humano a retirar o véu do real para dele encomendar, reservar, dispor (bestellen), enquanto o real é entendido como funcionalidade disponível (Bestand). Como se trata de uma requisição do homem, a provocação da essência técnica, reveladora do homem, da terra, do sistema solar e de seus planetas como fontes disponíveis à exploração não é um mero feito do ente humano, mas um estágio do destino da história do Ocidente.

Eis o grande gigantesco, "essa necessidade de instaurar uma dimensão de domínio incalculável (no sentido do ilimitado) por meio do cálculo que realiza a essência da maquinação como violência no exercício do poder" (RAMOS, 2015, p. 276). A violência (Gewalt) aqui não indica o uso da força física, mas compreende a imposição do ente, que busca ofuscar o aceno do seer, velando para si o abandono da essência fundante.

Em resumo, o que Heidegger faz nas Contribuições à Filosofia é apontar para o deslocamento do homem a caminho da lembrança do seer. Segundo o pensador, isso só pode emergir a partir do saber essencial, acenado apenas pelo mistério fundamental (Seyn), jamais a partir da impotência (Ohnmacht) da ciência e de sua maquinação. $O$ verdadeiro saber advém do insistir na questionalibilidade (Fraglichkeit) do seer, que guarda a sua dignidade no fato de que ele só se dá na raridade de seu aceno, na recusa como acontecimento apropriador (Ereignis). A ciência, petrificada no primado do ente, não se liberta dessa situação e ela mesma não deseja essa libertação, pois quanto mais progride, menos pode desejar sair da dimensão do ôntico.

\section{Considerações finais}

Vimos que o ser deixou de ser pensado no primado da maquinação, porque, para a vontade de poder do ente, a entidade se autodetermina na constância da presentidade. Isso indica a factibilidade, o fazer-se por si mesmo que, segundo Heidegger, parte da téchne como técnica em contraposição à eclosão mesma da physis. É a chamada preponderância do factível, isto é, a maquinação. Contudo, o

\footnotetext{
${ }^{10}$ Heidegger utiliza o termo alemão Machenschaft como um sinônimo que se aproxima de Technik, porque ambos trazem o sentido de disponibilidade que desafia o homem a desvelar o real.

${ }^{11} \mathrm{O}$ vocábulo advém de stellen (pôr alguma coisa de pé, contribuir, prover). O prefixo Ge- salienta, originalmente, "junto, com, reunião". Também é utizado como partícula necessária para a formação do Perfekt (estruturas textuais no tempo pretérito). "Gestell deve ser compreendido como a reunião (Ge-) de todos os modos do stellen (do colocar no lugar para tornar disponível) que agem conjuntamente na requisição técnica" (DUBOIS, 2004, p. 139).
} 
caminhar das meditações heideggerianas ruma para outra forma de estar no mundo, um salto antes nunca experienciado na história do Ocidente, que transita para a serenidade, tendo-se em vista a lembrança do mistério que funda o homem graças à sua doação essencial.

De certo modo, a meditação de Heidegger exposta neste texto visa fundar um espaço de decisão. $O$ homem precisa experimentar a carência da falta de indigência (falta de consciência de finitude) para compreender de que forma o seer o abandona e de que modo ele abandona o seer quando se petrifica na maquinação. Esse espaço técnico dos valores do ente permite - compreendido em termos da própria história do ser em seu primeiro princípio - o abandono do ser e a elevação da carência de indigência. As meditações heideggerianas, que visam a lembrança do ser, serenas frente às modulações tradicionais, não implicam na divulgação de novas doutrinas para promoverem o progresso das engrenagens humanas ao ápice da evolução da cultura e de seus valores. Mais profundamente, zela-se por um deslocamento radical do homem ao interior de sua pobreza e finitude, a fim de que ele visualize a mais extrema indigência na qual, desde sempre, esteve contido.

Entendemos que Heidegger busca abrir espaço na filosofia contemporânea ao que historicamente ficou esquecido. Trata-se da recepção humana ao toque inumano para se deslocar do estado atual maquinal, que nega a história do seer e que o esquece fixamente. É por isso que a elevação do homem, essa ida ao encontro do fundamento exige a mais intensa diligência para a verdade, solicita a presteza frente a essência do verdadeiro. Deve-se surgir a prontidão para recusar os esteios fixos nos domínios da correção e da reificação da maquinação e, assim, o ente não será mais o normativo para o seer. Faz-se mister, para Heidegger, o lançamento do pensamento tão para o interior do fundamento, que a verdade do seer passe a se clarear originariamente.

Enfim, pensando além de qualquer noção de progresso ou de desenvolvimento, quanto mais estivermos dispostos a permanecer (bleiben) no caminho das sendas do aberto (Seyn), mais fascinantes serão os voos à altitude do possível e mais intensos serão os sublimes acenos da ausência essencial. Ora, mas o que recebemos ao ingressarmos no que constantemente se vela e se ausenta? Possibilidades. Não sabemos quais, quando ou como, mas o mistério do ser pode, a partir do nosso carecer silencioso, presentear-nos.

Que assim seja.

Que o silêncio e a escuta tenham mais espaço do que os ruídos e os falatórios desmedidos.

Que o fluxo da vida tenha abertura para seguir o seu rumo sem manejos.

Que o curso do rio não seja interrompido.

Que a flor possa irromper e fluir.

Que os lirismos do poeta não cessem.

Que a mente do homem não seja suprema.

Porque "há" mais entre o céu e a terra do que a nossa simples finitude. 


\section{Referências:}

DUBOIS, Christian. Heidegger: introdução a uma leitura. Rio de Janeiro: Jorge Zahar, 2004.

HEIDEGGER, Martin. A origem da obra de arte. In: Caminhos de Floresta: Lisboa: Fundação Calouste Gulbenkian, 1998.

HEIDEGGER, Martin. A questão da técnica. In: Ensaios e conferências. Petrópolis, RJ: Vozes, 2001.

HEIDEGGER, Martin. Contribuições à filosofia (Do acontecimento apropriador). Rio de Janeiro: Via Verita, 2015.

HEIDEGGER, Martin. Platão: o sofista. Rio de Janeiro: Forense Universitária, 2012.

INWOOD, Michael. Dicionário Heidegger. Rio de Janeiro: Jorge Zahar, 2002.

ORTEGA Y GASSET, José. A rebelião das massas. Brasil: eBookLibris, 2001.

RAMOS, Daniel Rodrigues. O Ereignis em Heidegger. Teresópolis: Daimon, 2015.

RÜDIGER, Francisco. Elementos para a crítica da cibercultura: sujeito, objeto e interação na era das novas tecnologias de comunicação. São Paulo: Hacker Editores, 2002.

STEIN, Ernildo. Introdução ao pensamento de Martin Heidegger. Porto Alegre: EDIPUCRS, 2011.

TRAWNY, Peter. Adyton: a filosofia esotérica de Heidegger. Rio de Janeiro: Mauad $\mathrm{X}, 2013$, n.p.

Autor(a) para correspondência: Rodrigo Amorim Castelo Branco, Universidade de Brasília, Departamento de Filosofia - FIL, ICC Ala Norte- Bloco B - $1^{\circ}$ Andar (B1 624), Campus Universitário Darcy Ribeiro, Brasília, 70910-900, Distrito Federal - DF, Brasil. rodrigocasbr@hotmail.com 